\title{
Optic Nerve Evaluation in Idiopathic Intracranial Hypertension
}

W e read with great interest the article by Golden et al ${ }^{1}$ concerning the use of MR imaging with contrast-enhanced 3D-FLAIR imaging in patients with idiopathic intracranial hypertension (IIH). We would like to congratulate the authors for their fascinating study but would like to make some comments on the methodology used to conduct the research.

The authors used MR imaging in patients with IIH and control subjects to study the optic nerve and the optic nerve head and correlated their findings to the Frisén scale, an ophthalmologic scale for grading papilledema severity.

We have some concerns about the method used because Hayreh, ${ }^{2}$ in 2016, showed that the appearance of the optic nerve head does not simultaneously correlate with the measurement of intracranial pressure (ICP). In fact, as the authors correctly stated in the discussion, the appearance of papilledema is related to the elevated ICP that expresses itself with axoplasmic stasis and ischemia, with subsequent neurotoxicity. Thus, in the case of IIH, the optic disc could still appear edematous when the ICP is normalized or, to the contrary, could even be normal in the early phase of ICP increase.

Thus, recently, several articles have suggested using sonography to safely and noninvasively detect ICP and follow patients with high ICP, but unfortunately most of the authors used the B-scan technique, which, in our opinion, is not very reliable for this purpose. ${ }^{3,4}$

In our opinion, a standardized A-scan, first introduced by K.C. ${ }^{5}$ Ossoinig in late 1970 s is much more sensitive for this purpose because it can immediately detect the presence of high ICP or

http://dx.doi.org/10.3174/ajnr.A6091 even differentiate papilledema from pseudopapilledema (eg, in case of optic nerve drusen).

Furthermore, MR imaging is mandatory to exclude or determine the reason for the high ICP, but when a diagnosis of benign intracranial hypertension is entertained, we see no reason to use MR imaging to follow these patients when a cheaper and less invasive technique such as sonography can be used.

\section{REFERENCES}

1. Golden E, Krivochenitser R, Mathews N, et al. Contrast-enhanced 3D-FLAIR imaging of the optic nerve and optic nerve head: novel neuroimaging findings of idiopathic intracranial hypertension. AJNR Am J Neuroradiol 2019;40:334-39 CrossRef Medline

2. Hayreh SS. Pathogenesis of optic disc edema in raised intracranial pressure. Prog Retin Eye Res 2016;50:108-44 CrossRef Medline

3. Iaconetta G, De Bernardo M, Rosa N. Coronal axis measurement of the optic nerve sheath diameter. J Ultrasound Med 2017;36:1073 CrossRef Medline

4. De Bernardo M, Rosa N. Clarification on using ultrasonography to detect intracranial pressure. JAMA Ophthalmol 2017;135:1004-05 CrossRef Medline

5. Ossoinig KC. Standardized echography of the optic nerve. In: Till P, ed. Documenta Ophthalmologica Proceedings Series vol 55, Ophthalmic echography 13. Dordrecht: Springer Netherlands; 1990, 3-99

(1) M. De Bernardo

(1) L. Vitiello

(D) N. Rosa

Department of Medicine, Surgery, and Dentistry Scuola Medica Salernitana University of Salerno Salerno, Italy 